\title{
Pesquisa Quantitativa e/ou Qualitativa: distanciamentos, aproximações e possibilidades
}

\author{
Ricardo Franklin de Freitas Mussi \\ Licenciado em Educação Física pela Universidade do Estado da Bahia (UNEB); Mestre em Saúde Coletiva pela Universidade Estadual de \\ Feira de Santana (UEFS); Doutor em Educação Física pela Universidade Federal de Santa Catarina (UFSC). Líder do Grupo de Estudos, \\ Pesquisa e Extensão em Educação, Cultura e Saúde (GEPEECS/CNPq). Docente no Programa de Pós-graduação em Ensino, Linguagem e \\ Sociedade da Universidade do Estado da Bahia (UNEB) \\ 凶rimussi@yahoo.com.br
}

Leila Maria Prates Teixeira Mussi

Licenciada em História pela Universidade do Estado da Bahia (UNEB) e em Filosofia pelo Centro Universitário Claretiano; Mestre em História Regional e Local pela Universidade do Estado da Bahia (UNEB). Docente na Faculdade Santo Agostinho (FASA/Vitória da Conquista), na Universidade do Estado da Bahia (UNEB) e no Colégio Sêneca (Vitória da Conquista) 凶lmprates@hotmail.com

Emerson Tadeu Cotrim Assunção

Licenciado em Letras Vernáculas pela Universidade do Estado da Bahia (UNEB); Mestre em Letras: Cultura, Educação e Linguagens pela Universidade Estadual do Sudoeste da Bahia (UESB). Docente na Universidade do Estado da Bahia (UNEB)

凶emersonbrumado@hotmail.com

\section{Claudio Pinto Nunes}

Licenciado em Pedagogia pela Universidade do Estado da Bahia (UNEB); Mestre em Educação e Pesquisa pela Université Du Québec À Chicoutimi (Canadá); Doutor em Educação pela Universidade do Rio Grande do Norte (UFRN). Pós-Doutor em Educação pela Universidade Federal de Minas Gerais (UFMG). Líder do Grupo de Pesquisa Didática, Formação e Trabalho Docente (Difort/CNPq). Docente no Programa de Pós-Graduação em Educação da Universidade Estadual do Sudoeste da Bahia (UESB) 凶. claudionunesba@hotmail.com

\section{Resumo:}

A preocupação humana com a apreensão/compreensão da realidade no campo acadêmico-científico passa pela problemática de como abordar o objeto de maneira coerente e quais critérios teóricos-metodológicos podem/devem ser assumidos pelo pesquisador para o ótimo desenvolvimento da investigação. Neste sentido, o presente texto objetiva discutir as principais características das abordagens de pesquisa quantitativa e qualitativa. Metodologicamente trata-se de um estudo teórico, apresentado por meio do gênero acadêmico ensaio, pautado em incursões na literatura pertinente. O manuscrito apresenta as bases teórico-práticas que discursivizam as noções das abordagens de pesquisas qualitativa e quantitativa. $\mathrm{Na}$ primeira perspectiva o investigador supõe um universo de objetos comparáveis entre si, com enfoque nos indicadores numéricos. No segundo caso assumi-se um universo de sentidos, significados, motivos, aspirações, crenças, valores e atitudes focado nas relações, nos processos e nos fenômenos. Assim, as análises sinalizam que não há, necessariamente, oposição, suplementariedade ou complementaridade entre essas maneiras de fazer pesquisa. São modos diferentes do fazer científico para obtenção e tratamento das informações, portanto, relevantes para a ciência e sociedade, que podem e devem ser utilizadas no cotidiano científico. Diante das características das abordagens teórico-metodológicas, é fundamental indicar que suas bases e procedimentos são de natureza diferente, no entanto, é perfeitamente possível, a depender do objeto/objetivo da pesquisa, o diálogo e/ou encontro das duas abordagens.

Palavras-chave: Domínios científicos, métodos, ciência, análise estatística, análise qualitativa. 
Pesquisa Quantitativa e/ou Qualitativa:

distanciamentos, aproximações e possibilidades

\title{
Quantitative and/or Qualitative Research: distances, approaches and possibilities
}

\begin{abstract}
:
The human concern with the apprehension/understanding of reality in the academicscientific field goes through the problematic of how to approach the object in a coherent way and which theoretical-methodological criteria can/should be assumed by the researcher for the optimal development of the investigation. In this sense, the present text aims to discuss the main characteristics of quantitative and qualitative research approaches. Methodologically it is a theoretical study, presented through the academic genre essay, based on incursions in the relevant literature. The manuscript presents the theoretical and practical bases that discursivize the notions of qualitative and quantitative research approaches. In the first perspective, the researcher assumes a universe of comparable objects, focusing on numerical indicators. In the second case, we assumed a universe of meanings, meanings, motives, aspirations, beliefs, values and attitudes focused on relationships, processes and phenomena. Thus, the analyzes indicate that there is not necessarily opposition, complementarity or complementarity between these ways of doing research. They are different ways of doing science for obtaining and processing information, therefore, relevant to science and society, which can and should be used in scientific daily life. Given the characteristics of theoretical and methodological approaches, it is essential to indicate that their bases and procedures are different in nature, however, it is perfectly possible, depending on the object / objective of the research, the dialogue and/or meeting of the two approaches.
\end{abstract}

Keywords: Scientific domains, methods, science, statistical analyses, qualitative analysis.

\section{Investigación Cuantitativa y/o Cualitativa: distancias, enfoques y posibilidades}

\section{Resumen:}

La preocupación humana por la comprensión/comprensión de la realidad en el campo académico-científico pasa por la problemática de cómo abordar el objeto de manera coherente y qué criterios teórico-metodológicos pueden/deben ser asumidos por el investigador para el desarrollo óptimo de la investigación. En este sentido, el presente texto tiene como objetivo discutir las características principales de los enfoques de investigación cuantitativa y cualitativa. Metodológicamente es un estudio teórico, presentado a través del ensayo de género académico, basado en incursiones en la literatura relevante. El manuscrito presenta las bases teóricas y prácticas que discursivizan las nociones de los enfoques de investigación cualitativa y cuantitativa. En la primera perspectiva, el investigador asume un universo de objetos comparables, enfocándose en indicadores numéricos. En el segundo caso, asumimos un universo de significados, significados, motivos, aspiraciones, creencias, valores y actitudes centrados en las relaciones, procesos y fenómenos. Por lo tanto, los análisis indican que no hay necesariamente oposición, complementariedad o complementariedad entre estas formas de hacer investigación. Son formas diferentes de hacer ciencia para obtener y procesar información, por lo tanto, relevantes para la ciencia y la sociedad, que pueden y deben usarse en la vida científica diaria. Dadas las características de los enfoques teóricos y metodológicos, es esencial indicar que sus bases y procedimientos son de naturaleza diferente, sin embargo, es perfectamente posible, dependiendo del objeto/objetivo de la investigación, el diálogo y / o la reunión de los dos enfoques.

Palabras claves: Dominios científicos, métodos, ciencia, análisis estadístico, análisis cualitativo. 


\section{INTRODUÇÃo}

Não existe uma fórmula mágica e única para realizar uma pesquisa ideal; talvez não exista nem existirá uma pesquisa perfeita. A investigação é um produto humano, e seus produtores são falíveis. ... fazer pesquisa não é privilégio de alguns poucos gênios. ... É melhor ter trabalho de pesquisa imperfeito a não ter trabalho nenhum. (RICHARDSON, 2011, p.15)

$\mathrm{O}$ anseio pela tomada de consciência frente aos acontecimentos e produções cotidianas da humanidade foi, e continua sendo, importante estímulo para sua compreensão da realidade. Então, cabe aos investigadores realizarem as pesquisas propriamente ditas e a estruturação de propostas metodológicas adequadas ao fazer científico.

Mesmo diante do questionamento crítico sobre a fragilidade da substituição do senso comum, produzido e acessado no cotidiano da humanidade, pelo conhecimento científico, desenvolvido e disponibilizado por um grupo seleto (ROUSSEAU, 1971), a segunda categoria de pensamento assumiu papel de certo destaque nas sociedades humanas, especialmente no campo acadêmico.

A pesquisa é a atividade concreta no processo de constituição e desenvolvimento científico, possibilitando a produção, identificação e descoberta do conhecimento, respostas para perguntas específicas e soluções de problemas. Esta atividade pauta-se fundamentalmente na exigência da escolha intencional dos métodos disponíveis, que conduzirão o desenvolvimento ideal para a compreensão do objeto analisado, também nomeável de realidade.

Todos que ingressam no ambiente científico devem aceitar a impossibilidade da apreensão plena do real, o que, no entanto, não impossibilita aproximações bastante acuradas, permitindo o crescimento do conhecimento sobre determinada temática (ALBERTI, 2005).

A melhor cobertura e compreensão dos acontecimentos sociais demanda uma diversidade metodológica. Esta dinâmica motivou a constituição de diversos métodos e técnicas para o planejamento e a execução do processo investigativo, que, devendo ser apresentadas em linguagem simples, clara e objetiva, para que possam ser acompanhadas e/ou reaplicadas pelos interessados, conforme suas próprias diretrizes.

Neste sentido, estas propostas podem ser organizadas quanto a sua maneira de abordar o objeto ou intenção investigativa como de natureza quantitativa e qualitativa. A primeira é pautada em explicações matemáticas e modelos estatísticos, enquanto a segunda 


\section{Pesquisa Quantitativa e/ou Qualitativa: \\ distanciamentos, aproximações e possibilidades}

tem enfoque nas interpretações das realidades sociais (BAUER; GASKELL; ALLUM, 2008) e, segundo Flick (2002), preocupa-se em analisar casos concretos em suas particularidades locais e temporais, embasando-se das expressões e atividades das pessoas em seus contextos de vida.

A batalha epistemológica travada entre os defensores de cada uma dessas maneiras de pesquisar parecem prejudiciais para a ciência de maneira geral. Pois, é cabível a compreensão de que "existem problemas que podem ser investigados por meio de metodologia quantitativa, e há outros que exigem diferentes enfoques e, consequentemente, uma metodologia de conotação qualitativa" (RICHARDSON, 2011, p.79). Não obstante, o entremeio científico se faz, em muitos casos, alinhando dados quantitativos com explicações qualitativas (MINAYO, 2012).

As realidades são construídas e as dinâmicas analíticas também são e, ambas, atendem às demandas momentâneas e/ou duradouras, seja de maneira individual e/ou de modo coletivo/comunitário. Então, é pertinente redirecionar o questionamento sobre a veracidade do método, para o quanto ele é útil na facilitação quanto ao desbravamento do terreno empírico que se tem a frente (PERRONE, 1977). Ou seja, a atenção do estudioso deve ser direcionada no quanto a abordagem e as técnicas selecionadas auxiliarão na análise apropriada do problema, permitindo que o pesquisador atinja um resultado coerente e suficiente.

Mais importante que a opção da abordagem metodológica, nas etapas de planejamento e execução da pesquisa, "os procedimentos devem ser descritos com clareza, para que o leitor acompanhe virtualmente as etapas do processo" (CANZONIERI, 2010, p.17). Esta ação gera confiança na profundidade das informações apresentadas.

A adoção por uma das abordagens para apropriação do objeto, mais que uma questão burocrática, relaciona-se à escolha dos procedimentos que serão aplicados, com base teórica na concepção e direcionamento da pesquisa (FILSTEAD, 1979). A opção pela perspectiva qualitativa ou quantitativa reflete a própria formação ou maneira como o pesquisador percebe o objeto e/ou o sujeito e sinaliza afetamentos históricos e ideológicos que formam o pesquisador.

$\mathrm{Na}$ abordagem quantitativa, a ênfase é na análise, pelo exame dos componentes separadamente, enquanto a qualitativa visa "compreender o significado de uma experiência dos participantes, em um ambiente específico, bem como o modo como os componentes se mesclam para formar o todo" (JONES, 2007, p.298). 
Assim, o presente estudo, que tem caráter ensaístico, pretende discutir as principais características das abordagens de pesquisa quantitativa e qualitativa. Não obstante, nos posicionamos, linguístico-discursivamente, no texto como sujeitos afetados pela transição do paradigma dominante de pesquisa para o paradigma emergente (SANTOS, 1989), que estão postos nas discussões aqui empreendidas. Nesse sentido, acreditamos que esse texto contribua para a superação do pensamento ingênuo sobre a idealização de soluções para problemas investigativos, sendo um texto capaz da geração de contribuição para sistemas explicativos analíticos mais ou menos complexos, que devem e merecem ser criticados e, portanto, avaliados, executados e modificados para que sejam melhor entendidos, ajustados e tragam avanços.

\section{PESQUISA QUANTITATIVA: CARACTERÍSTICAS E FUNDAMENTOS}

O pensamento científico moderno nasceu há quase quatro séculos, quando a Ciência torna-se independente da Filosofia e da Religião, pela delimitação de seu objeto, objetivo e método. A partir deste paradigma, a ciência assume, como seu objeto de estudo as leis da natureza e a interação entre seus fenômenos, a filosofia ocupa-se do ser humano enquanto ser e, a religião mantem-se com as questões da fé (TURATO, 2005).

Assim, entende-se que cada uma destas maneiras de conhecer/compreender se dedicam a objetos diferentes, todas igualmente importantes na e para produção de saberes, apenas com perspectivas diversas e, consequentemente, com propósitos e proposições de naturezas distintas. No entanto, é percebido um conflito que pretende a equivocada hierarquização entre essas maneiras de conhecimento/compreensão.

O avanço da possibilidade científica de apreensão da realidade promoveu a estruturação do Positivismo,

[...] um movimento que enfatiza a ciência e o método científico (a física) como única fonte de conhecimento, estabelecendo forte distinção entre fatos e valores, e grande hostilidade com a religião e a metafísica. Insiste na existência de uma ordem natural com leis que a sociedade deve seguir. Além disso, a realidade não pode ser conhecida em sua totalidade; portanto, apenas se estudam dados individuais. (RICHARDSON, 2011, p.33)

A pesquisa quantitativa pretende e permite a determinação de indicadores e tendências presentes na realidade, ou seja, dados representativos e objetivos, opondo-se à ciência aristotélica, com a desconfiança sistemática das evidências e experiência imediata. 


\section{Pesquisa Quantitativa e/ou Qualitativa: \\ distanciamentos, aproximações e possibilidades}

Seu eixo central é a materialização físico-numérica no momento da explicação, com uma desvalorização da subjetividade e da individualidade.

"A matemática fornece à ciência moderna, não só o instrumento privilegiado de análise, como também a lógica da investigação, como ainda o modelo de representação, da própria estrutura da matéria” (SANTOS, 2005, p.27). Por esta perspectiva, a informação científica significa quantificar, mesmo sabendo-se que "ordem e regularidade só podem ser estabelecidas, de forma aproximada, em termos médios e sobre um grande número de indivíduos" (MINAYO; SANCHES, 1993, p.241).

A abordagem quantitativa aceita que a melhor possibilidade explicativa científica é aquela que não se interessa pelo singular, o individual, o diferenciado, ou seja, o pessoal. Nesta abordagem, o interesse é no coletivo, naquilo que pode ser predominante como característica do grupo.

Essa dinâmica promove em seu interior o fortalecimento da estatística, diante da sua potencialidade na análise de dados e possibilidade de inferência, pedindo apenas o respeito à variabilidade aleatória amostral (MINAYO; SANCHES, 1993). A capacidade de generalização é sua principal característica, o acontecido na amostra será assumido para a população, que não precisa ter sido estudada integralmente.

De maneira restrita, tem-se que, negativamente, na abordagem quantitativa, seus métodos são frágeis quanto à validade interna (quanto a medir o que se pretende medir) (SERAPIONI, 2000), apesar de serem regularmente confiáveis para a validade externa (passíveis de generalização para grandes grupos).

As investigações quantitativas não são capazes de resolver ou responder a todos os problemas sociais, mas, permitem, diante do atendimento ao rigor metodológico, o acesso e divulgação de valiosas informações sobre os sujeitos e/ou populacionais. Mas, mesmo cumprindo as exigências no controle investigativo, os resultados não se transferirão para outras situações sociais (RICHARDSON, 2011).

A qualidade dos estudos quantitativos apresenta importante proximidade com a complexidade do modelo estatístico, do nível de planejamento, da variação e assertividade na seleção das variáveis, dos instrumentos aplicados e da fundamentação teórica que permitirão a melhor análise da hipótese.

No entanto, cabe ressalta que os abusos ou excessos na utilização dos procedimentos estatísticos, seja por desconhecimento ou ignorância às suas limitações pelo pesquisador, podem motivar suspeitas quanto à validade dos resultados da análise (ALTMAN, 1991). Os 
testes estatísticos devem ser selecionados a partir de uma intencionalidade teórica frente ao objeto e desenho do estudo previamente determinados, caraterísticas que minimizarão a possibilidade de falácia científica das informações apresentadas. Então, aceita-se que como a estatística "preocupa-se com o problema relativo ao tipo de informações que são analisadas: se colocarmos informações irrelevantes, teremos resultados irrelevantes" (BAUER; GASKELL; ALLUM, 2008, p.24).

Ainda podem ser realizadas as seguintes críticas teóricas sobre os métodos quantitativos (RICHARDSON, 2011): a concepção positivista de ciência; a redução da ciência ao campo do observável e a separação entre fatos e seus contextos; a ênfase no dado empírico e sua reificação; insistência na neutralidade e objetividade dos dados; a insistência na ciência livre de valores; percepção do mundo como um objeto que deve ser controlado tecnologicamente pelo ser humano.

Neste sentido, os conflitos se apresentam nas seguintes questões: nem sempre é de interesse o determinismo mecânico para análise e compreensão da 'humanidade'; desse modo, a investigação não deveria apenas testar hipóteses, mas, analisar ou compreender as múltiplas possibilidades diante de um problema real. A imparcialidade não seria uma vantagem, mas possibilidade de negligência da realidade, tornando o dado sem significado e simplório, apesar da complexidade, carregado de valores e simbolismos, sem os quais não há sentido, pois, não podem ou não devem responder a manipulações laboratoriais.

Positivamente, a pesquisa quantitativa contribui importantemente para o entendimento da presença e/ou influência de caraterísticas isoladas e/ou associadas, que podem embasar ações para seu enfrentamento prioritário, como ocorre de maneira recorrente no embasamento, planejamento, execução e avaliação das políticas públicas.

Apesar de sua longa presença histórica, é enganosa a afirmativa que a plena estruturação e clareza dos conflitos presentes na pesquisa quantitativa estão em vias de finalização. Pois, pensadores e estudiosos seguem proporcionando novas perspectivas analíticas, o que contribui para melhor elucidação de suas especificidades, com questionamentos enriquecedores para continuidade de sua discussão. 


\section{PESQUISA QUALITATIVA: CARACTERÍSTICAS E FUNDAMENTOS}

Os cientistas eram persuadidos de que a linguagem matemática era um critério indispensável de cientificidade e o único capaz de trazer "provas definitivas" ao mundo empírico, ainda que se possa ver, agora, que tal não era o caso. (PIRES, 2008, p.54)

A pesquisa quantitativa dominou por algum tempo o cenário acadêmico científico. Mas, no século XIX, surgiram sinais de insatisfação com o paradigma científico clássico. 0 acelerado ritmo do progresso trouxe instabilidade à própria ciência, e, paulatinamente, foise abandonando a ideia de que a verdade científica seria una e única, mesmo no âmbito das Ciências Exatas e Naturais (COSTA, 1996). Nesse sentido, teorias clássicas passaram a ser refutadas e/ou substituídas, assumindo-os como instrumentos e conceitos provisórios para entendimento da realidade.

As abordagens qualitativas de pesquisa se desenvolveram paralelamente às quantitativas, focando sua atenção na indução, nos mecanismos subjacentes aos comportamentos e as interpretações destes pelos próprios sujeitos, valorizando a diversidade (ALAMI; DESJEUX; GARABUAU-MOUSSAOUI, 2010). Estudos com essa abordagem objetivam o aprofundamento da compreensão de um fenômeno social por meio de entrevistas em profundidade e análises qualitativas da consciência articulada dos atores envolvidos no fenômeno. Nessa perspectiva, a pesquisa qualitativa permite "dar voz às pessoas, em vez de tratá-las como objetos" (BAUER; GASKELL; ALLUM, 2008, p.30).

Karl Max foi um dos precursores da revolução na maneira de pensar. O materialismo histórico e dialético, aplicação de sua teoria ao estudo da evolução histórica das sociedades humanas, propôs que o modo de produção dos bens materiais condiciona a vida social, política e intelectual que, por sua vez, interage com a base material.

O materialismo histórico é

[...] a ciência filosófica do marxismo que estuda as leis sociológicas que caracterizam a vida da sociedade, de sua evolução histórica e da prática social dos homens, no desenvolvimento da humanidade. O materialismo histórico significou uma mudança fundamental na interpretação dos fenômenos sociais que, até o nascimento do marxismo, se apoiava em concepções idealistas da sociedade humana. (TRIVIÑOS, 2006, p.51)

Aderir a essa matriz epistêmica, então, exige uma concepção dialética da realidade natural e social e do pensamento, a materialidade dos fenômenos e que estes são possíveis de 
conhecer. Existe uma realidade objetiva fora da consciência e esta consciência resulta da evolução do material, o que significa que a matéria é o princípio primeiro e a consciência é o aspecto secundário, o derivado.

As pesquisas orientadas pelo método dialético revelam a historicidade do fenômeno e suas relações, em nível mais amplo, situam o problema dentro de um contexto complexo, ao mesmo tempo, estabelece e aponta as contradições possíveis dentre os fenômenos investigados. Mais ainda, a investigação qualitativa é alicerçada na inseparabilidade dos fenômenos e seu contexto, pois, as opiniões, percepções e significados serão mais bem compreendidos com maior profundidade a partir da contextualização (RIBEIRO; SOUZA; COSTA, 2016).

Esse fator se faz mais visível nas Ciências Sociais, notando-se uma diferenciação de seu objeto frente às Ciências Naturais, já que esta é mutável, histórica e dinâmica (SUASSUNA, 2008). Em outras palavras, "baseia-se no suposto que a sociedade está em movimento constante, que o mundo social e nossa compreensão dele estão mudando constantemente, limitando o calor da generalização" (RICHARDSON, 2011, p.101).

A partir da década de 1970 essa busca metodológica se consolida baseada principalmente em críticas filosóficas, políticas e técnicas aos métodos hegemônicos, fortemente relacionados ao sistema socioeconômico utilizado para promover, ou justificar, o empobrecimento da maioria da população (RICHARDSON, 2011). Estudos com essa abordagem objetivam o aprofundamento da compreensão de um fenômeno social por meio de entrevistas em profundidade e análises qualitativas da consciência articulada dos atores envolvidos no fenômeno.

A variação do objeto das Ciências Sociais seria decorrente da não-univocidade da linguagem e das diferenças no desempenho de papéis por parte dos diversos atores sociais. Estas ciências, então, seriam marcadas pelo pluralismo teórico e se concretizariam, mais do que como metateorias, como um conjunto de postulados básicos que orientam a pesquisa, aliados a procedimentos de seleção dos fatos e reconstrução de fenômenos.

Minayo (2009, p.12) afirma que o objeto das Ciências Sociais é histórico visto que,

[...] cada sociedade humana existe e se constrói num determinado espaço e se organiza de forma particular e diferente de outras. Por sua vez, todas as que vivenciam a mesma época histórica têm alguns traços comuns, dado o fato de que vivemos num mundo marcado pelo influxo das comunicações. 


\section{Pesquisa Quantitativa e/ou Qualitativa: \\ distanciamentos, aproximações e possibilidades}

As sociedades vivem o presente, agarradas em suas memórias e práticas do passado e é desta maneira que se preparam para o futuro. Portanto, a provisoriedade, o dinamismo e a especificidade são características de qualquer questão social. Por isso, também, as crises têm reflexo tanto no seu desenvolvimento como na decadência das teorias sociais que as explicam.

Minayo (2009, p.13) ressalta que nestas ciências existe uma "identidade entre sujeito e objeto", já que a pesquisa nessa área lida com seres humanos que, por diversos motivos, assemelham-se com o investigador e aí se deve atentar para o comprometimento e a tentativa de uma maior neutralidade do pesquisador, mesmo esta afirmando que "não existe uma ciência neutra. Toda ciência [...] passa por interesses e visões de mundo historicamente criadas, embora suas contribuições e seus efeitos teóricos e técnicos ultrapassem as intenções de seus próprios autores" (MINAYO, 2009, p.13).

Lévy-Strauss (1975, p.215) já apresentava posicionamento similar no que se refere a esta questão do comprometimento do pesquisador, pois "numa ciência, onde o observador é da mesma natureza que o objeto, e o observador é, ele próprio, uma parte de sua observação". Assim, a questão ideológica deve ser bem discutida e elaborada. O que ocorre é que na investigação social, a relação entre pesquisador e seu campo de estudos se estabelece definitivamente. Portanto, o processo de conhecimento parte desde a concepção do objeto, a pesquisa propriamente dita e os resultados e aplicações desta.

Deste modo, Minayo (2009, p.14) afirma que o objeto das Ciências Sociais é essencialmente qualitativo, porque "a realidade social é a cena e o seio do dinamismo da vida individual e coletiva com toda a riqueza de significados dela transbordante".

A pesquisa qualitativa permite através de seus métodos estudar as especialidades de cada sociedade visto que "seu foco é a exploração do conjunto de opiniões e representações sociais sobre o tema que pretende investigar" (GOMES, 2009, p.79).

Assim, a pesquisa qualitativa nos permite enveredar por situações que os números muitas vezes não conseguem responder. Um desses fatores pode ser utilizado através do uso da memória como fonte de pesquisa. A Fonte Oral vem conquistando a adesão de teóricos que a defendem como um meio legal e importantíssimo de se pesquisar em alguns setores das História e de outras ciências. Sobre a utilização da memória Nora (1993, p.9) retrata que

[...] a memória é vida, sempre carregada por grupos vivos e, nesse sentido, ela está em permanente evolução, aberta a dialética da lembrança e do esquecimento, 
inconsciente de suas deformações sucessivas, vulnerável a todos os usos e manipulações, suscetível de longas latências e repentinas revitalizações.

Quando Nora (1993) fala sobre a questão do inconsciente e das vulnerabilidades da memória, certamente não é questionando a validade dessa metodologia, mas sim chamando a atenção para como o pesquisador deve estar atento e com a sua criticidade aguçada para esses prováveis contratempos, ou até mesmo questões assim podem acabar enriquecendo ainda mais o trabalho.

Challoub (2003, p.17) advoga que todo pesquisador deve ir além de suas expectativas, deve ler e interpretar seu objeto nas entrelinhas, não deixando passar detalhe algum por que

[...] detalhes aparentemente marginais e irrelevantes são formas essenciais de acesso a uma determinada realidade; são tais detalhes que podem dar a chave para redes de significados sociais e psicológicos mais profundos, inacessíveis por outros métodos.

Para Demo (1998, p.101), pesquisa qualitativa significa "o esforço jeitoso de formalização perante uma realidade também jeitosa. Trata-se de uma consciência crítica de propensão formalizante da ciência, sabendo indigitar suas virtudes e vazios”. Dito de outra maneira, este espaço jeitoso a que Demo se refere, é a questão de que a pesquisa qualitativa olha com prioridade para os aspectos qualitativos da realidade, mas sem desprezar os aspectos quantitativos.

Mas engana-se quem acredita que sem muito estudo de bibliografias sobre seu tema e um conhecimento maior sobre seu objeto de pesquisa se sairá bem na utilização da pesquisa qualitativa. Minayo (2009, p.20) afirma que

[...] o pesquisador que assumir tal objeto de pesquisa deve partir para uma busca bibliográfica sobre cada uma das expressões citadas e trabalhá-las historicamente, com as divergências e convergências teóricas, para só depois colocar sua posição e suas hipóteses.

Dessa forma, a autora nos confirma que, para a utilização da pesquisa qualitativa, o pesquisador deve estar muito bem preparado e, sobre essa afirmação, Demo (1998, p.101) também contribui comentando que

[...] um questionário aberto pode ser a porta de entrada para um mundo de representações sociais mais subjetivas, e por isso mais profundas e determinantes, à medida que permite a fala descontraída, realista e natural, a não-linearidade de respostas sobre realidades tipicamente não-lineares. Mas, ainda assim ou 
precisamente por isso, precisa ser bem organizado e garantir, entre outras coisas, que em cada novo questionário se trata do mesmo tema, da mesma pesquisa, da mesma análise, ou seja, deve existir um contexto sistemático e lógico, até mesmo para podermos comparar e inferir. É erro crasso imaginar que de conversas soltas, amadoramente conduzidas ou mal conduzidas, se possa extrair alguma análise mais profunda, ou que de algumas pessoas indagadas se possa inferir conclusões que abalem o universo. Ademais, se no dado empírico, quantitativo ou pretensamente quantitativo, a manipulação corre solta, que dizer de dados qualitativos desprovidos de um mínimo de sistematização.

Com essa análise, Demo demonstra a seriedade que o pesquisador deve oferecer ao estudo prévio das bibliografias já consagradas para que este não perca oportunidades e, o mais importante, que não perca a confiança que o objeto de pesquisa estará depositando nele. Na esteira desse pensamento,

\begin{abstract}
Apreender a subjetividade não significa identificar formas através das quais ela se reconhece e é reconhecida. Implica apreender o processo de emergência das figuras que ela desenha. Constitui a própria trama uma vez que não possui um antes já dado. Trata-se da composição dos diversos universos que habitam cada existência em seu estar no mundo. Universos estes sempre sujeitos a novos arranjos, a novas errâncias, dependendo da força dos condicionamentos sociais. (FERREIRA; GROSSI, 2004, p.46)
\end{abstract}

Complementarmente, a pesquisa qualitativa se caracteriza pela sua flexibilidade de adaptação durante seu desenvolvimento, por se ocupar de objetos complexos, por englobar dados heterogêneos, pela capacidade de descrever profundamente vários aspetos da vida social e por sua abertura ao mundo empírico (PIRES, 2008). Dado que se observa quando se compreende que

o pesquisador é o principal instrumento da coleta e análise dos dados. Ele interage com os participantes, e sua sensibilidade e percepção são essenciais na busca e no processamento de observações e respostas. O modo como o pesquisador administra as respostas durante a coleta e a análise dos dados afetam a qualidade desses dados e as conclusões. (JONES, 2007, p.299)

Mas, também não deve ser defendido o pensamento ingênuo de que "a metodologia qualitativa é a melhor escolha por não querer trabalhar com dados estatísticos, por ser uma alternativa ou complementaridade à metodologia quantitativa" (CANZONIERI, 2010, p.18).

A autenticidade, ou validação, da pesquisa qualitativa pode ser verificada pela aceitação da sua importância pelos participantes (BAUER; GASKELL; ALLUM, 2008), ou seja, sem impacto direto e real na sociedade a pesquisa qualitativa não seria validada. "Neste caso, a recepção dos achados por quem e para que propósito é um ponto crucial" (BAUER; GASKELL; 
ALLUM, 2008, p.35) capaz de promover a validade da investigação, independentemente de sua confirmação matemática ou estatística. Desse modo, a

[...] validade pode ser analisada em termos da administração reflexiva da relação entre as opiniões dos entrevistados e um processo mais abrangente de análise histórica e estrutural. Essa é uma combinação complexa que exige um trabalho cuidadoso em cada etapa do processo de pesquisa. Proporciona, porém, uma oportunidade única de ir além das aparências superficiais do dia-a-dia. Também, permite fazer uma análise teórica dos fenômenos sociais baseada no cotidiano das pessoas e em uma aproximação crítica das categorias e formas como se configura essas experiências diárias. (RICHARDSON, 2011, p.103)

Não obstante, pode-se considerar que a pesquisa qualitativa é caracterizada por uma abordagem de pesquisa peculiar, uma vez que respeita e valoriza a subjetividade, como fonte de informação válida. "A pesquisa qualitativa enfatiza a 'essência' do fenômeno. A visão de mundo das pessoas varia de acordo com a percepção de cada um, sendo bastante subjetiva" (JONES, 2007, p.298).

Negativamente, é possível citar que enquanto a pesquisa quantitativa "possui um amplo repertório de formalidades estatísticas a seu dispor [...] na pesquisa qualitativa não está ainda bem desenvolvido" (BAUER; GASKELL; ALLUM, 2008, p.25) - também é citado o risco que o pesquisador corre em assumir os pressupostos dos participantes, podendo assumir os erros ocorridos na proposta positivista acrítica.

O “aspecto mais importante da pesquisa qualitativa é o conteúdo interpretativo, e não o excesso de preocupação com o procedimento" (JONES, 2007, p.297); ou seja, o "que a discussão sobre a pesquisa qualitativa tem conseguido foi desmistificar a sofisticação estatística como único caminho para se conseguir resultados significativos" (BAUER; GASKELL; ALLUM, 2008, p.24).

\section{CONSIDERAÇÕES FINAIS}

Do ponto de vista Antropológico, podemos dizer que sempre existiu preocupação do homo sapiens com o conhecimento da realidade. (MINAYO, 2009, p.9).

Por mais que perspectivas das abordagens quantitativa e qualitativa em pesquisa sejam de natureza diferentes, é fundamental que seja entendido que não são antagônicas, nem suplementares e/ou complementares. A depender do tema, o pesquisador, de maneira intencional, deve perceber a necessidade de sua incursão numa abordagem quantitativa e/ou 


\section{Pesquisa Quantitativa e/ou Qualitativa: \\ distanciamentos, aproximações e possibilidades}

qualitativa, para o atingimento suficiente da análise do objeto, considerando a utilização ideal da perspectiva cientifica. Portanto, a utilização de uma ou outra maneira do fazer científico deve corroborar intencionalmente com a possibilidade de compreensão dos mais diferentes/diversos objetos em análise.

Paripassu, tanto a pesquisa quantitativa quanto a pesquisa qualitativa devem ser empregadas em diversas apostas investigativas que tenham o mundo e as coisas do mundo como possibilidade empírica a serem explicadas pela ciência. Dito de outro modo, as abordagens são faces e feições empregadas em situações específicas que tenham a relação homem-sociedade como objeto de estudo e possibilidade concreta de explicação das diferentes manifestações da realidade.

Portanto, desfeita a ideia de oposição entre abordagens quanti e quali, é possível e importante que tratemos de suas especificidades metodológicas. Assim posto, de maneira sintética e didática, a pesquisa quantitativa supõe um universo de objetos de investigação que são comparáveis entre si, ao tempo que utiliza de indicadores numéricos sobre determinado fenômeno investigável. Enquanto a pesquisa qualitativa trabalha com um universo de sentidos, significados, motivos, aspirações, crenças, valores e atitudes, o que corresponde a um fazer científico focado nas relações, nos processos e nos fenômenos que não devem ser tratados pela racionalização de variáveis.

É inegável, portanto, que são tipos de pesquisa (sem generalizações, claro!) que se imbricam no cotidiano do pesquisador. Vem daí, justamente, a ideia de pesquisa quantiquanlitativa para descrever metodologias que fazem usos de estratégias diversas com vistas a uma finalidade comum: (re)fazer ciência e/em sociedade.

Destarte, o pesquisador não deve mais se deixar atrair pela ideia ingenuamente crédula da busca da 'verdade' científica, mas, direcionar-se para o desenvolvimento de análises coerentes da realidade e suas transformações. O mesmo deve ser capaz da adoção intencional de variadas técnicas, conforme a perspectiva de abordagens do objeto. Já que, em face da movência discursiva, os sujeitos agem e reagem, pela linguagem, em suas posiçõessujeito. Então, em face da natureza instável dos objetos, as dinâmicas da pesquisa qualitativa se diferem da quantitativa, mas não se colocam em campos opostos.

Tudo isso evidencia que os pesquisadores, independentemente da abordagem teóricometodológica assumida, desenvolvem seus estudos analogamente, mas, com a finalidade precípua de atender funções epistemológicas similares. Neste sentido, com o propósito de analisar ou explicar a realidade, é fundamental a sensibilidade do pesquisador quanto a 
possibilidade de (re)ver nos dados nuances que, embora apenas pareçam óbvias, explicitam/explicam a essência do objeto/sujeito.

Por fim, é necessário frisar que uma abordagem não é superior ou inferior à outra, pois, ambas dinâmicas de conhecimento, quando bem fundamentadas e praticadas, promoverão informações pertinentes para o desenvolvimento da humanidade.

\section{REFERÊNCIAS}

ALAMI, S.; DESJEUX, D.; GARABUAU-MOUSSAOUI, I. Os métodos qualitativos. Petrópolis: Vozes, 2010

ALBERTI, V. Manual de História Oral. 3 ed. Rio de Janeiro: FGV, 2005.

ALTMAN, D. G. Statistics in medical journals: developments in the 1980s. Statistics in Medicine, v.10, p.1897913, 1991.

AMARAL, L. V. Tipos de Pesquisa em Educação Física. Lecturas: Educación Física y Deportes, v.17, n.167, 2012.

BAUER, M. W.; GASKELL, G.; ALLUM, N. C. Qualidade, quantidade e interesses do conhecimento. In: BAUER, M. W.; GASKELL, G. (Orgs.) Pesquisa Qualitativa com textos, imagem e som: um manual prático. Petrópolis: Vozes, 2008.

CANZONIERI, A. M. Metodologia da Pesquisa Qualitativa na Saúde. Petrópolis: Vozes, 2010.

CHALHOUB, S. Visões da Liberdade, uma história das últimas décadas da escravidão na corte. São Paulo: Cia. das Letras, 2003.

COSTA, M. V. Novos olhares na pesquisa em Educação. In: COSTA, M.V. (Org.). Caminhos investigativos: novos olhares na pesquisa em Educação. Porto Alegre: Mediação, 1996. p. 9-17.

DEMO, P. Pesquisa Qualitativa: busca de equilíbrio entre forma e conteúdo. Revista Latino-americana de enfermagem, v.6, n.2, p.89-104, 1998.

FERREIRA, A.C.; GROSSI, Y.S. A narrativa na trama da subjetividade: perspectivas e desafios. História Oral, v.7, p.41-59, 2004.

FILSTEAD, W. J. Qualitative Methods: a needed perspective in evaluation research. In: COOK, T. D.: REICHARDT, C. S. (Orgs.) Qualitative and Quantitative Methods in Evaluation Research. Beverly Hills: Sage, 1979. 
FLICK, U. Introdução à pesquisa qualitativa. Porto Alegre: Artmed, 2002.

GOMES, R. Análise e Interpretação de dados de pesquisa qualitativa. In: MINAYO, M. C. S. Pesquisa Social: teoria, método e criatividade. Petrópolis: Vozes, 2009. p.

JONES, F. P. Pesquisa qualitativa. In: THOMAS, J. R.; NELSON, J. K.; SILVERMAN, S. S. Métodos da Pesquisa em Atividade Física. Porto Alegre: Artmed, 2007.

LÉVY-STRAUSS, C. Aula Inaugural. In: ZALUAR, A. (org). Desvendando máscaras sociais. Rio de Janeiro: Francisco Alves, 1975. p.211-244.

LÜDORF, S. M. A. Panorama da pesquisa em educação física da década de 90: análise dos resumos de dissertações e teses. Revista da Educação Física/UEM, Maringá, v. 13, n. 2, p. 19-25, 2. sem. 2002.

MINAYO, M. C. S. Análise qualitativa: teoria, passos e fidedignidade. Ciência \& Saúde Coletiva, v.17, n.3, p.62126, 2012.

Pesquisa Social: teoria, método e criatividade. Petrópolis: Vozes, 2009.

MINAYO, M. C. S.; SANCHES, O. Quantitativo-Qualitativo: oposição ou complementaridade? Caderno de Saúde Pública, v.9, n.3, p.239-262, 1993.

NORA, P. Entre memória e história: A problemática dos lugares. São Paulo: Projeto História, 1993.

PERRONE, L. Metodi Quantitativi della Ricerca Sociale. Milão: Feltrinelli, 1977.

PIRES, A. P. Sobre algumas questões epistemológicas de uma metodologia geral para as ciências sociais. In: POUPART, J.; DESLAURIERS, J.; GROULX, L.; LAPERRIERE, A.; MAYER, R.; PIRES, A. A Pesquisa Qualitativa: enfoques epistemológicos e metodológicos. Petrópolis: Vozes, 2008.

RIBEIRO, J.; SOUZA, D. N.; COSTA, A. P. Investigação qualitativa na área da saúde: por quê? Ciência e saúde coletiva, v.21, n.8, p.2324, 2016.

RICHARDSON, R. J. Pesquisa Social: métodos e técnicas. 3 ed. 13 reimp. São Paulo: Atlas, 2011.

ROUSSEAU, J. Oeuvres Complète. v.2. Paris: Seuil, 1971.

SANTOS, B. S. Discurso sobre as ciências. São Paulo: Cortez, 2005. 
. Introdução a uma ciência pós-moderna. Rio de Janeiro: Graal, 1989

SERAPIONI, M. Métodos Qualitativos e Quantitativos na Pesquisa Social em Saúde: algumas estratégias para a investigação. Ciência e Saúde Coletiva, v.5, n.1, p.187-192, 2000.

SUASSUNA, L. Pesquisa qualitativa em Educação e Linguagem: histórico e validação do paradigma indiciário. Revista Perspectiva, v.26, n.1, p.341-77, 2008.

TRIVIÑOS, A. Introdução à pesquisa em ciências sociais: a pesquisa qualitativa em educação. São Paulo: atlas, 2006.

TURATO, E. R. Métodos Qualitativos e Quantitativos na Área da Saúde: definições, diferenças e seus objetivos de pesquisa. Revista de Saúde Pública, v.39, n.3, p.507-14, 2005.

\section{(cc) $\overline{E Y}$}

Este trabalho está licenciado com uma Licença Creative Commons - Atribuição 4.0 Internacional. 